\title{
UV Protecting Behavior of Imidazole Based Zno Hybrid Thin Films for Sunscreen Applications
}

\author{
O. Akbar Basha, S. Mohammed Ghouse, I. Pugazhenthi, V. Vishnu Vardan
}

\begin{abstract}
U V$ radiations near visible region effects the human, and it causes many skin diseases. UV light not only effects human and also decolorize most of the textile fabrics. It degrades anticorrosive coatings and it triggers the corrosion over the metal surface. The protection of $U V$ radiations has lot of attraction in the field of engineering research field to prepare sunscreen coatings. This work explains the preparation and characterization of Poly ( $\mathrm{N}$-vinyl imidazole)/ZnO by different techniques. The UV protective behaviors of prepared polymer composite thin films, make them as promising candidates for $U V$ shielding and sunscreen applications.

Keywords: Polymer nanocomposite, Thin films, UV Protective Coating,
\end{abstract}

\section{INTRODUCTION}

The UV radiations reach from sunlight to earth is harmful for human skin. Due to decrease in the thickness of Ozone layer, these UV radiations causes very harmful skin diseases [1]. The UV light with wavelength below $300 \mathrm{~nm}$ has been filtered out by ozone layer but UV light in the range between 300 to $400 \mathrm{~nm}$ cannot be filtered out by ozone. Now a days researchers are involving to discover different UV absorbing materials. Nano materials with UV absorbing properties have been attracted, because of their photovoltaic nature which absorbs UV light effectively and these nanomaterials were incorporated into polymer matrix namely polymethyl methacrylate (PMMA) [2,3]. These polymer nanocomposites have been drawn in the form of thin films which does not allow UV radiations to enter due to effective absorption of UV light by nanomaterials [4].

Manuscript published on November 30, 2019

* Correspondence Author

O. Akbar Basha*, Assistant Professor, Department of Chemistry, Annamacharya institute of technology and sciences, Rajampeta, Andhra Pradesh-516 126. Email: othuru.akbar@gmail.com

S.Mohammed Ghouse, Assistant Professor, Department of Chemistry, Annamacharya institute of technology and sciences, Rajampeta , Andhra Pradesh- 516 126. Email: shamog.edu@gmail.com

I.Pugazhenthi, Assistant Professor, Department of Chemistry, Annamacharya institute of technology and sciences, Rajampeta, Andhra Pradesh-516 126. Email: pugalchemist@gmail.com

V.Vishnuvardan Assistant Professor, Department of Chemistry, Annamacharya institute of technology and science, Rajampet, Andhra Pradesh- 516126.

(C) The Authors. Published by Blue Eyes Intelligence Engineering and Sciences Publication (BEIESP). This is an open access article under the CC-BY-NC-ND license http://creativecommons.org/licenses/by-nc-nd/4.0/
Among different nanomaterials, $\mathrm{ZnO}$ is very cheap, ecofriendly and easy to prepare. ZnONps are wide band gap which makes it to compatible for UV absorption applications [5-7]. Here the synthesis of Poly(viniyl imidazole)/ZnO nano thin films have been reported for UV shielding purposes. We have characterized the crystalline, morphological, thermal properties and optical properties of both thin films with and without ZnONPs.

\section{MATERIALS AND METHODS}

\section{SYNTHESIS OF NVI}

Poly(N-vinyl-2-imidazole) (PNVI) was prepared by free radical solution polymerization. 1g N-vinylimidazole (NVI) monomer was taken in toluene in which $60 \mathrm{mg}$ of AIBN radical initiator was added. Polymerization was conducted at $85^{\circ} \mathrm{C}$ for $3 \mathrm{~h}$. After cooling $50 \mathrm{ml}$ of Hexane was added to precipitate pure PNVI polymer powder which was vacuum dried at $40^{\circ} \mathrm{C}$ [8].

\section{PREPARATION OF NVP-ZNO COMPOSITE THIN FILMS}

Exactly $1 \mathrm{~g}$ of NVI is stirred into $30 \mathrm{ml}$ of Ethanol at Room temperature to get homogenous solution. $2.0 \mathrm{wt} \%$ of $\mathrm{ZnO}$ NPs are added to the above solution with sodium dodecylsulphate (SDS) the solution is stirred in warm condition. The mixture was cooled and fabricated on glass substrates $\left(1 \mathrm{~cm}^{2}\right)$ by using spin coating method at $4500 \mathrm{rpm}$. Then the coated substrate is dried at $60^{\circ} \mathrm{C}$. the composite thin films deposited on the glass surface has to be peeled out and kept in vacuum.

\section{CHARACTERIZATION TECHNIQUES}

The crystalline and amorphous nature of synthesized materials were analyzed by Bruker D8 advance $\mathrm{x}$-ray diffractometer, over the range of angular angle $(2 \theta)$ in between $5-80^{\circ}$. The interaction of polymer and nanoparticles were analyzed FTIR spectra of SHIMADZU 8400 spectrophotometer. HITACHI S-4800 Type II spectrophotometer was used to study morphology of polymer thin films. UV blocking properties of prepared thin films have been analyzed by JASCO 670 spectrophotometer (DRS). 


\section{UV Protecting Behavior of Imidazole Based Zno Hybrid Thin Films for Sunscreen Applications}

\section{RESULTS AND DISCUSSION}

\section{XRD STUDIES}

The XRD spectra of PNVI and PNVI-ZnO films have been showed in the Fig.1. The peak at $2 \theta=22.6$ corresponding to (1 $\left.0 \begin{array}{ll}1 & 1\end{array}\right)$ plane is representing the amorphous nature of PNVI thin films. The presence of small crystalline peaks is the characteristic nature of ZnONPs, thus these Patterns suggests that the successive incorporation of ZnONps in the polymer matrix.

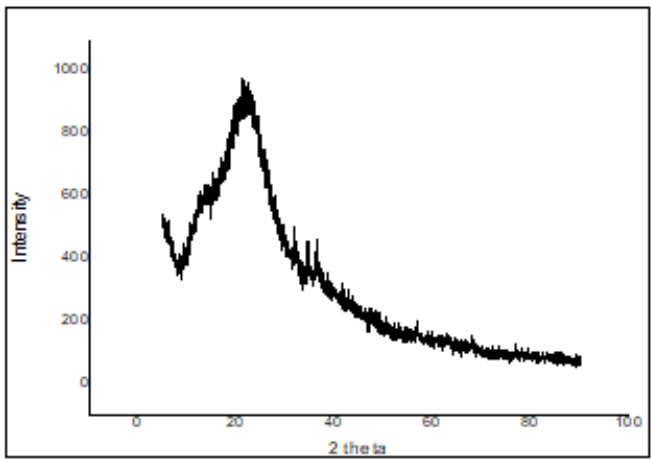

Fig-1 XRD patterns of PNVI-ZnO composite film

\section{FTIR STUDIES}

The absorption for PNVI and its $\mathrm{ZnO}$ composite thin films at $3108 \mathrm{~cm}^{-1}$ and $2956 \mathrm{~cm}^{-1}$ signifies the $\mathrm{C}-\mathrm{H}$ (ring) and $\mathrm{C}$ $\mathrm{H}$ (chain) stretching, respectively (Fig.2). 1633 and 1527 $\mathrm{cm}^{-1}$ are related to $\mathrm{C}=\mathrm{C}$ and $\mathrm{C}=\mathrm{N}$ stretching of imidazole ring. Polymer composite thin films show the same pattern with additional band at $483 \mathrm{~cm}^{-1}$ which is due to $\mathrm{Zn}-\mathrm{O}$ vibrations. It is apparent from the fig 2 that the intensity of peaks are getting decrease with addition of nano particle. It is due to the compatibility of ZnONPs with polymer

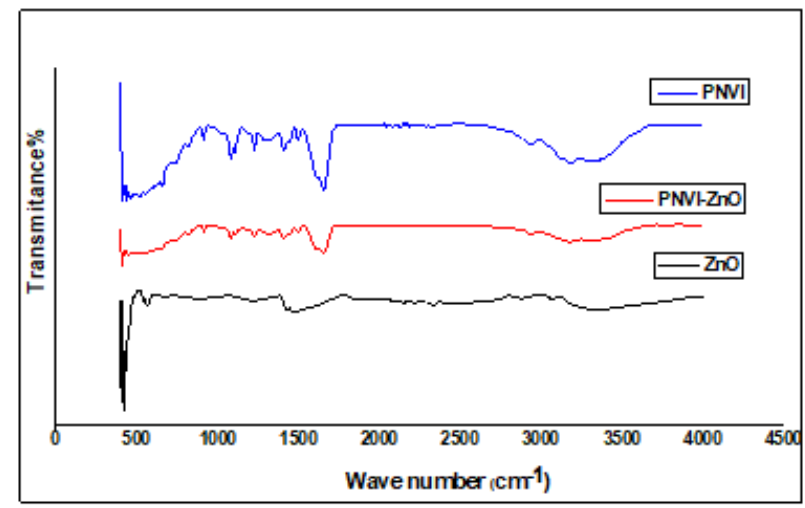

Fig-2 FTIR spectra of PNVI and its ZnO composite thin film

\section{MORPHOLOGICAL ANALYSIS OF THIN FILMS}

The pristine polymer shows the morphology of smooth and homogenous surface. The incorporation of $\mathrm{ZnO}$ nano particles in the polymer matrix alters its homogenous surface morphology to heterogeneous.
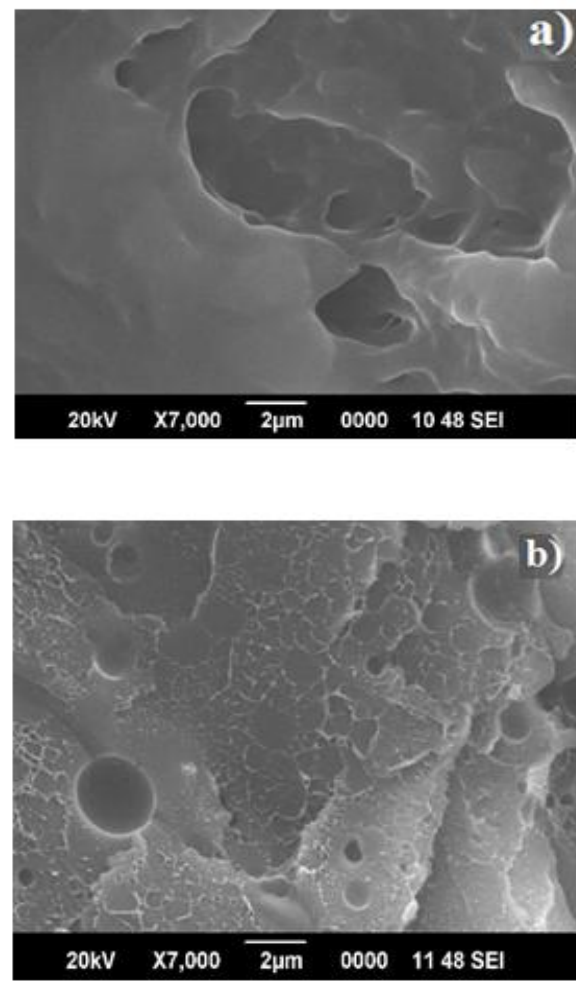

Fig-3 FESEM of a) PNVI, b) PNVI-ZnO composite

\section{THERMOGRAVIMETRIC ANALYSIS}

The initial weight loss up to $3-5 \%$ of PNVI and its $\mathrm{ZnO}$ nanocomposite thin film at $150^{\circ} \mathrm{C}$ is due to removal of water.

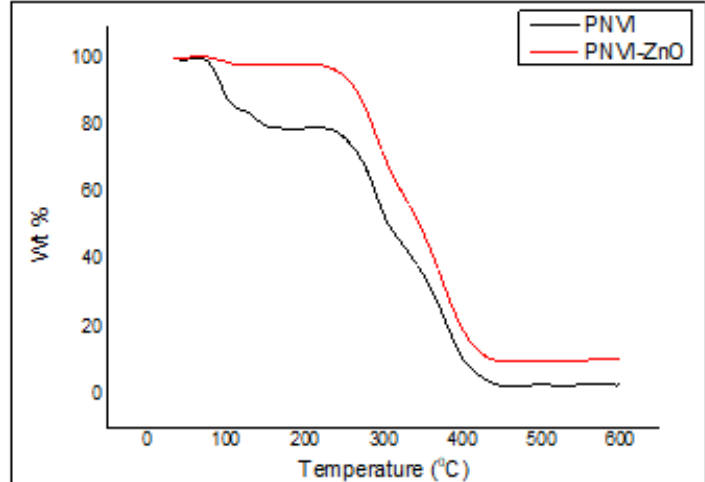

Fig -4 Thermogravimetric Analysis of TGA of PNVI thin films

The residue of $72.26 \%$ of PNVI remaining is observed after the initial degradation, whereas $95.17 \%$ of residues remaining were left for poly ( $\mathrm{N}$-vinyl imidazole)/ZnO (2.0 $w t \%)$ correspondingly. TG curves for pure polymer and its $\mathrm{ZnO}$ nanocomposite thin film exhibit a remarkable drop between 250 and $350{ }^{\circ} \mathrm{C}$ as shown in Fig. 4. The degradation of the nanocomposite thin film has shifted to a higher temperature range than that of neat polymer.

\section{OPTICAL STUDIES}

To investigate the optical properties, the absorption spectra of the PNVI and PNVI-ZnO-(2wt\%) of ZnO loading were taken and shown in Fig.5a. The absorption maxima for pure PNVI at $216 \mathrm{~nm}$, which is due to the p-p* 
electronic transitions of Imidazole. The absorbance spectra of the PNVI-ZnO showed an additional absorbance band at $356 \mathrm{~nm}$ corresponding to $\mathrm{ZnO}$ nanoparticle. Fig. 4 a indicates that the absorbance of nanocomposite increases with the increase of ZnONPs content, which is comparable with ZnONPs doped in functional conducting polymers [11]. The increase in UV absorbencies due to the absorption of incident radiation by free electrons of ZnONPs and get excited to the PNVI [12]

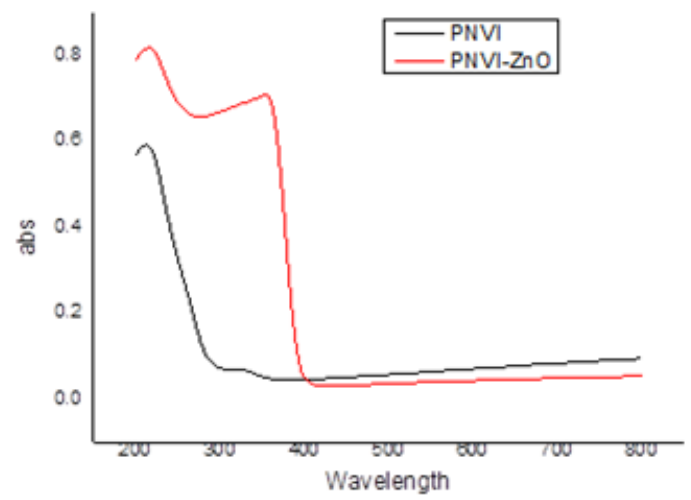

Fig-5a UV absorption spectra of the PNVI and PNVI$\mathrm{ZnO}$

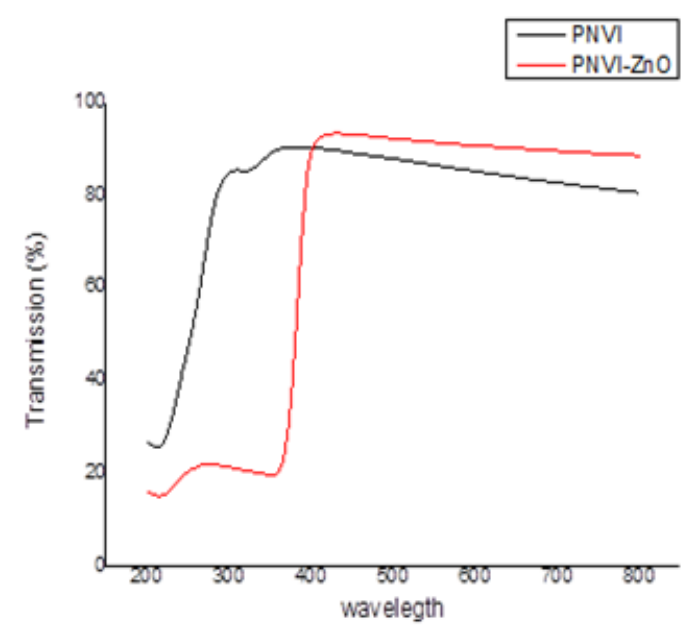

Fig-5b UV- transmittance spectra of the PNVI and
PNVI-ZnO

It is well known that the Imidazole. moiety possesses strong electron acceptor character, therefore PNVI /ZnO can be used to UV-filtering materials such as fibers and coatings [13]. The transmittance spectra of PNVI and its $\mathrm{ZnO}$ nanocomposite films with $2.0 \mathrm{wt} \% \mathrm{ZnO}$ filler contents transmittance at two different wavelengths, that is at $356 \mathrm{~nm}$ and $550 \mathrm{~nm}$ is shown in Fig.5b. The incorporation of $2.0 \mathrm{wt} \% \mathrm{ZnO}$ decreases the transmittance of the resultant nanocomposite at UV region [14]. Hence the intensity of absorption maxima in the range of $350-400 \mathrm{~nm}$ increases with ZnONPs loading. The $2.0 \mathrm{wt} \% \mathrm{ZnONPs}$ showed 20\% of transmittance in UV region that infers that the composite has strong UV blocking efficiency. The loss of $80 \%$ transmittance in this UV wave length range indicates, that the synthesized film could be used as UV-blocking materials.

\section{CONCLUSION}

In conclusion the UV blocking properties of PVNI has been improved by incorporation of ZnONPs. It shows enhanced UV absorption and decreased Transmittance. The loss of transmittance below 380nm makes the composite film as promising UV shielding coatings.

\section{ACKNOWLEDGEMENT}

Authors thank to Management, Principal and Head of the department (H\&S) for their support for these works.

\section{REFERENCES}

1. Popov A.P, Priezzhev A.V, lademann J and Myllyla. "TiO nanoparticles as an effective UV-B radiation skin- Protective compound in sunscreens"2005, V-38,P-2564-2570.

2. Zhanh Y., wang X., Yongxin L Shuvan S and Dapeng L. "Highly transparent bulk PMMA/ZnO nanocomposites with bright visible luminescence and efficient UV-Shielding capacity”. 2012, J. Mater. Chem., V-22, P-11971-11977

3. Li S., Toprak M. S., Jo Y.S., Dobson J., Kim D.K and Mummhed M. "Bulk Synthesis of Transparent and Homogeneous Polymeric Hybrid Materials with ZnO Quantum Dots and PMMA”,2007, Advanced materials, V-19, P- 4347-1352.

4. Alessandro D., Mauro M., Elena f., Vittorio P and Giuliana I. "ZnO for application in photocatalysis: From thin films to nanostructures. Materialsscience in semiconductor processing" 2017, V-69, P-44-51.

5. Yewei Z., Shendong Z., Xiaoyong X and jingguo H. "Transparent and UV shielding ZnO@PMMA nanocomposite films”. Optical Materials, 2013, V-36,P-169-172.

6. Rui D., Cheng B., Oingfeng D., Fawen G., Yongbo Y and Fang Z., An Ultraviolet-to-NIR Broad Spectral Nanocomposite Photodetector with Gain

7. Alessio B., maximilian D., Pierendrea 1 and Nostro P. Synthesis and characterization of $\mathrm{ZnO}$ nanoparticles: application to textiles as UV-absorbers. Journal of Nanoparticle Research 2008; 10:679 689.

8. Peing L., Zhixing S., Preparation and Characterization of PMMA/ZnO Nanocomposites via insitu polymerization Method. Journal of Macromolecular Science, Part B 2006;45:131-138.

9. Xing $H_{\text {., }}$ Ma H., Fu M., Xue $X$., Zhang $X$. and Dong $X$ Preparation of g-C3N4/ZnO composites and their enhanced photocatalytic activity Materials technology Advanced performance materials, 2015;30:122-127.

10. Pragathi F., Subhashis G and Surojit P., Synthesis of $\mathrm{ZnO} / \mathrm{Au}$ and $\mathrm{ZnO} / \mathrm{Ag}$ nanoparticles and their photocatalytic application using UV and visible light, RSC Adv.2014;4:24962.

11. Andrey N., Elena L., Alexandrova I and Scherbakov P, Hybrid active layers from a conjugated polymer and inorganic nanoparticles for organic light emitting devices with emission color tuned by electric field. J. Phys. D. Appl. Phys. 2009; 42:105108.

12. M. Khan M., Chen M., Wei C., Tao J and Huang N., Synthesis at the nanoscale of $\mathrm{ZnO}$ into poly(methyl methacrylate) and its characterization, Appl. Phys. A.,2014;117: 1085-1093.

13. Shanshool H.M., Yahaya H., Yunus W. M. M and Abdullah I. Y., Investigation of energy band gap in polymer/ZnO nanocomposites, J. Mater. Sci. Mater. Elec. 2016; 27: 9804-9811.

14. Demir M.M., Koynov K., Akbey U, Bubeck C., Park I., Lieberwirth I and Wegner G, Optical properties of composites of PMMA and surface-modified zincite nanoparticles, Macromolecules, 2007; 40: 1089-1100.

\section{AUTHORS PROFILE}

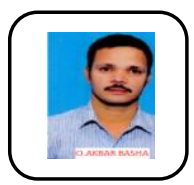

The author received a bachelor degree in Loyola degree College in Pulivendula affiliated to SV university Tirupati. A master degree in SV university Tirupati, Andhra Pradesh. He has six years of teaching and experiences. 
UV Protecting Behavior of Imidazole Based Zno Hybrid Thin Films for Sunscreen Applications

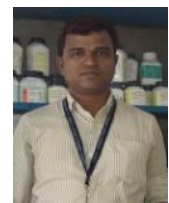

The author received bachelor degree during 2001-2004

and Master degree during 2006-2008 from Sri

Venkateshwara University, Tirupati and also completed

Bachelor of Education from Maulana Azad Nationa

Urdu University, Hyderabad during 2005-2006, author

having 8 years of academic experiences.

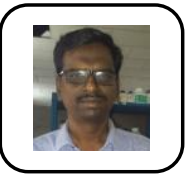

The author received his UG degree in chemistry from RKM Vivekananda College, Chennai. Later he completed PG in Chemistry from Madras Christian College, Chennai.

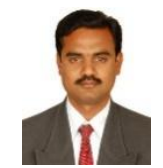

The author received his $\mathrm{PG}$ and $\mathrm{PhD}$ degree in environmental science from Sri Venkateshwara University, Tirupati. 